\title{
Viral RNA in the bloodstream suggests viremia occurs in clinically ill rabies-infected mice
}

\author{
Donald L. Lodmell*, Derek E. Dimcheff, Larry C. Ewalt \\ Laboratory of Persistent Viral Diseases, Rocky Mountain Laboratories, National Institute of Allergy and Infectious Diseases, Hamilton, MT 59840, USA
}

Received 1 August 2005; received in revised form 16 September 2005; accepted 16 September 2005

Available online 19 October 2005

\begin{abstract}
Data regarding the occurrence of a viremia during rabies virus infections are contradictory. Here, we attempted to clarify the dissimilar results using a qualitative TaqMan PCR assay to detect viral RNA in blood of mice that had been injected intramuscularly with rabies virus. Viral RNA was detected at two different intervals. Initially, RNA was present in blood of 30/32 (94\%) mice, from $1 \mathrm{~h}$ to 2 days after injection of virus. The RNA in the blood at this time most likely resulted from trauma to blood vessels at the injection site and leakage of the inoculated virus into the circulation. Thereafter, from 3 to 30 days, viral RNA was undetectable in the blood of 37 mice that remained free of clinical disease. However, and more importantly, viral RNA was detected again in 21/25 (84\%) mice that became clinically ill and were exsanguinated 2-4 days after the onset of paralysis. The presence of viral RNA in blood of the clinically ill mice might have been due to an escape of virus into the bloodstream as a result of viral replication induced injury in the central nervous system and other tissues. Anti-rabies virus neutralizing antibody was detected in sera of 11/21 (52\%) clinically ill mice whose blood was positive for rabies viral RNA. The presence of viral RNA in the bloodstream of mice that developed clinical rabies suggested that a viremia might occur in rabies-infected mice. Thus, the current opinion that a viremia does not occur in experimental or natural rabies infections of other species might need to be re-evaluated.
\end{abstract}

Published by Elsevier B.V.

Keywords: Rabies; Rabies virus; Viremia; TaqMan PCR; Mice

\section{Introduction}

It is well known that rabies virus is transmitted from the site of exposure to the central nervous system (CNS) via peripheral nerves (Dean et al., 1963; Murphy and Bauer, 1974; Murphy, 1977). It is less clear whether infectious virus is ever present in blood during infection. Nonetheless, several studies support the occurrence of a viremia. An early observation by Hertwich showed that dogs with fresh wounds develop rabies after blood from rabid animals is placed into the wounds (Burne, 1970). In addition, rabies virus is occasionally detected in blood of mice injected with tissues from dead rabid foxes (Atanasiu et al., 1970). A viremia has also been reported in rabies-infected rabbits (Baratawidjaja et al., 1965). The viremia was confirmed by detecting immunnofluorescent rabies viral antigens in brains of mice that developed rabies after intracranial (IC) inoculation

\footnotetext{
* Corresponding author. Tel.: +1 406363 9360; fax: +1 4063639286.

E-mail address: djrabid@aol.com (D.L. Lodmell).
}

of the rabbit leucocytes. In contrast, it has been shown that mice do not develop rabies after an IC injection of undiluted blood from mice that are exhibiting symptoms of rabies (Borodina, 1958; Schindler, 1961) or after injection with the buffy coat of rats that had been infected with rabies virus $3-120 \mathrm{~h}$ previously (Baer et al., 1965).

The possibility that virus may be "masked" in the blood, and thus, undetectable in assays for infectious virus, was initially addressed by Gribencha and Barinsky (1982). They determined that a viremia occurs in $100 \%$ of mice receiving the immunosuppressant cyclophosphamide prior to an intramuscular (IM) injection of rabies virus. In contrast, a viremia does not occur in mice that are not treated with cyclophosphamide. It was presumed that neutralizing antibody present in mice that were not immunosuppressed prevents the detection of infectious virus (Gribencha and Barinsky, 1982). Support for this possibility has been shown in cortisone-injected animals. Seven days after injection of virus, an interval in which CNS signs of infection are evident, virus is present in the blood of cortisone treated hamsters. In contrast, a viremia is not detectable in hamsters that 
are not treated with cortisone (Sims et al., 1963). Notably, it is known that cortisone injections interfere with neutralizing antibody production in rabbits (Burns et al., 1960) and rats (Shukeir and Nosik, 1965) that are being immunized with rabies vaccines.

Investigations with parabiotic rats having a common blood circulation, but not a neural connection, have also resulted in disparate results concerning the occurrence of a viremia during rabies virus infections. In an argument against viremia, Schweinburg (1930) and Schindler (1966) reported that only the parabiotic partner injected with virus develops rabies. In contrast, Becker and Zunker (1980) showed that a street rabies virus, but not a "fixed" rabies virus, "traveled" via the blood stream from the infected to the non-infected parabiotic partner in 24/26 (92\%) pairs of rats. Disparate viremic results have also been reported in three studies in which the spread of rabies virus was investigated after injection of virus into rear footpads of animals in which portions of the sciatic and saphenous nerve were removed. Initially, it was determined that rabies virus is usually transmitted via peripheral nerves from the site of exposure to the CNS (Dean et al., 1963). However, it was suggested that bloodborne transmission is possible, but it is the exception rather than the rule. In a second study, sciatic and saphenous neurectomy before an intraplantar injection of rabies virus proved $100 \%$ effective in preventing rabies in rats (Baer et al., 1965). In contrast, virus was shown to by-pass severed sciatic and saphenous nerves reaching the brain through the blood in approximately $20 \%$ of rats that had been injected in the footpad with virus (Kitselman et al., 1967).

Thus, it remains unclear whether a viremia occurs during rabies virus infections. This investigation did not ask whether rabies virus might invade the CNS from the blood. Instead, we wanted to know whether viral RNA is ever present in blood during a rabies infection. The presence of viral RNA would suggest that a viremia (infectious virus) might occur in rabies-infected mice. If so, the current opinion that virus is most likely not present in the blood of rabies-affected animals might need to be revisited. The ultra-sensitive and specific real-time TaqMan PCR assay was used to detect viral RNA. The assay has been used previously to detect rabies viruses, as well as other nonsegmented negative strand RNA viruses (Hughes et al., 2004). In addition to its sensitivity and specificity, the TaqMan assay is not influenced by anti-viral factors in blood, such as complement, neutralizing antibody or other non-antibody factors (Burrer et al., 2001) that could mask the presence of infectious virus.

\section{Materials and methods}

\subsection{Design of TaqMan primer and probes}

TaqMan real-time rtPCR primers and probe were designed using Primer Express 2.0 software (Applied Biosystems, Foster City, CA) based on the sequence of the nucleoprotein gene of a rabies virus isolated from a bat (Lodmell, 1983). The probe was labeled with a reporter dye (FAM) on the $5^{\prime}$ end and a quencher dye (TAMRA) on the $3^{\prime}$ end. Primer and probe sequences are listed in the $5^{\prime}-3^{\prime}$ orientation and are as follows: forward primer, TGTGGCCTTGGCAGATGAC; reverse primer, CCTC-
CGGACTCCTGGTTTC; probe, CAGTCAATTCTGATGACGAGGACTACTTCTCTGG.

\subsection{TaqMan PCR}

TaqMan reactions were set-up in 96-well plates containing $30 \mu 1 /$ well of Master Mix (Applied Biosystems, Branchburg, $\mathrm{NJ}) ; 5 \mu \mathrm{l}$ of RNA $(0.1 \mu \mathrm{g} / \mu \mathrm{l})$ was added to each well. After mixing and centrifugation, triplicate samples of each mixture were added to a 384-well plate. The plates were covered with optical adhesive and transferred to an ABI Prism 7900 Sequence Detection System (Applied Biosystems). Each sample was reverse transcribed and PCR amplified using TaqMan one-step rtPCR Master Mix in a total reaction volume of $10 \mu \mathrm{l}(0.167 \mu \mathrm{g}$ RNA). Reactions were performed using $500 \mathrm{nM}$ of each primer and $250 \mathrm{nM}$ of the TaqMan probe. Triplicate samples of cellular RNA from the brain of a rabies-infected mouse (positive control), cellular RNA from the brain of an uninfected mouse (negative control) and ultra pure nuclease-free water were included with each assay. A threshold cycle of $<40$ was considered positive for the presence of rabies viral RNA.

\subsection{Use of the TaqMan PCR assay to detect rabies viral RNA within total cellular RNA from rabies virus-infected cell cultures and brain tissue}

Total cellular RNA was isolated from a $10 \%$ brain suspension prepared from paralyzed mice injected in the cranium with rabies virus or mouse neuroblastoma (MNB) cells infected $48 \mathrm{~h}$ previously with rabies virus at a multiplicity-of-infection-of-one. Samples of each preparation were adjusted to contain $1000 \mathrm{ng} / \mu \mathrm{l}$ of cellular RNA and serial 10-fold dilutions through $10^{-7}$ of the $1000 \mathrm{ng} / \mu \mathrm{l}$ preparation were assayed for rabies viral RNA.

\subsection{Detection of rabies viral RNA and infectious rabies virus in the identical tissue preparation: comparative sensitivity analysis}

Serial 10 -fold dilutions (from $2 \times 10^{6}$ to $2 \times 10^{-1}$ mouse intracranial lethal dose $\left.50\left(\operatorname{ICLD}_{50}\right)\right)$ were made from a $10 \%$ brain suspension prepared from paralyzed rabies virus-infected mice. Six isoflurane anesthetized weanling mice were injected IC with $0.03 \mathrm{ml}$ of each brain dilution. The mice were observed for the development of clinical rabies for 30 days after injection of virus. MNB cell monolayers were overlaid with $0.2 \mathrm{ml}$ of each brain dilution and incubated for $24 \mathrm{~h}$. Thereafter, the monolayers were stained and observed for rabies specific fluorescent foci. Cellular RNA was isolated from the identical brain dilutions and triplicate $0.03 \mathrm{ml}$ (equivalent to the volume injected IC) samples were evaluated by TaqMan PCR for rabies viral RNA.

\subsection{Virus injection, exsanguination and isolation of RNA from blood}

Mice were injected $(0.075 \mathrm{ml})$ in the right anterior tibialis muscle with a $10 \%$ brain suspension prepared from rabies virusinfected paralyzed mice $\left(1 \times 10^{2}\right.$ mouse intramuscular lethal 
dose $_{50}$ infectious units of virus). Preliminary experiments determined that $70 \%$ of mice developed clinical rabies 10-16 days after an i.m. injection with this concentration of virus. Animals were isoflurane anesthetized and exsanguinated (an average of $0.7-1.0 \mathrm{ml} / \mathrm{mouse}$ ) from severed axillary arteries or directly from the heart using a needle (25 gauge, $1 / 2^{\prime \prime}$ ) and $1.0 \mathrm{ml}$ syringe. Clinically ill mice were exsanguinated 2-4 days after onset of clinical signs of infection; $50 \mu$ l of the harvested blood was removed for detection of serum neutralizing antibody. The remaining blood, including the clot, was then added directly to $4 \mathrm{ml}$ of TRIzol reagent (Life Technologies Inc., Gaithersburg, MD). Total cellular RNA was extracted according to the manufactures' instructions and suspended in $200 \mu \mathrm{l}$ of ultrapure water (Gibco, Invitrogen Corporation, Grand island, NY); $30 \mu \mathrm{l}$ of $2 \mathrm{M}$ sodium acetate was added to the RNA followed by $500 \mu \mathrm{l}$ of $100 \%$ ethyl alcohol $\left(-20^{\circ} \mathrm{C}\right)$. The mixtures were stored at $-70{ }^{\circ} \mathrm{C}$ until prepared for analysis. Triplicate samples, each containing $0.167 \mu \mathrm{g}$ of cellular RNA, were analyzed for rabies viral RNA.

\subsection{Mice}

Female Balb/cByJ mice, 16-20 weeks of age, were purchased from the Jackson Laboratory (Bar Harbor, ME). The animal facilities and animal care and use programs of the RML are fully accredited by the Association for Assessment and Accreditation of Laboratory Care International and they function in accordance with all United states Department of Health and Human Services and National Institutes of Health regulations and standards.

\subsection{Neutralizing antibody assay}

Rabies virus neutralizing antibody titers were determined as previously described (Smith et al., 1973) as modified (Lodmell et al., 1998). Reciprocal dilutions of individual sera that reduced the number of fluorescent foci $50 \%$ were noted. Positive controls included anti-sera with known concentrations of International Units (IU) of rabies virus neutralizing antibody: a rabies hyperimmune mouse serum pool and the United States Standard Human Rabies Immunoglobulin R2.

\section{Results}

Initial experiments were done to compare the capability of the TaqMan PCR assay to detect rabies viral RNA in total cellular RNA from rabies virus-infected cell cultures or brain tissue of rabies-infected mice. The assay was highly sensitive. The endpoint for detection of viral RNA in both brain and cell culture preparations was in the $10^{-4} \mathrm{ng}$ concentration of cellular RNA (Table 1).

Next, we compared the sensitivity to detect infectious virus using IC inoculation of weanling mice or production of viral foci in cell culture with the sensitivity of the TaqMan assay to detect viral RNA. The sensitivities of the TaqMan assay and IC inoculation of weanling mice were identical having positive endpoints in the preparation containing two mouse ICLD $_{50}$ of virus. The production of viral foci in tissue culture was 10-fold less sen-
Table 1

TaqMan PCR endpoint detection of rabies viral RNA within total cellular RNA of rabies virus-infected cell cultures and brains of rabies-affected mice ${ }^{\mathrm{a}}$

\begin{tabular}{lll}
\hline Cellular RNA concentration (ng) & \multicolumn{2}{l}{ Source of viral RNA } \\
\cline { 2 - 3 } & Cell culture & Brain tissue \\
\hline $10^{2}$ & $+^{\mathrm{b}}$ & + \\
$10^{1}$ & + & + \\
$10^{0}$ & + & + \\
$10^{-1}$ & + & + \\
$10^{-2}$ & + & + \\
$10^{-3}$ & + & + \\
$10^{-4}$ & + & + \\
$10^{-5}$ & $-^{\mathrm{c}}$ & - \\
$10^{-6}$ & - & $\mathrm{nt}^{\mathrm{d}}$ \\
$10^{-7}$ & - & $\mathrm{nt}^{\mathrm{d}}$
\end{tabular}

${ }^{a}$ Cellular RNA was isolated from brains of paralyzed mice injected with rabies virus or MNB cells infected $48 \mathrm{~h}$ previously with rabies virus. Ten-fold dilutions of the cellular RNA containing $10^{2}$ to $10^{-7} \mathrm{ng} / 0.03 \mathrm{ml}$ were prepared and analyzed for rabies viral RNA.

b (+) Positive for rabies viral RNA ( $<40$ threshold cycles).

c $(-)$ Negative for rabies viral RNA ( $>40$ threshold cycles).

d Not tested.

sitive (Table 2). Importantly, the last dilution tested $\left(2 \times 10^{-1}\right.$ mouse ICLD ${ }_{50}$ ), which should not have contained rabies virus, was negative for both infectious virus (6/6 survivors) and rabies viral RNA ( $>40$ threshold cycles) (Table 2).

The first two experiments determined that the TaqMan assay was very sensitive in detecting viral RNA within ng concentrations of total cellular RNA. Lastly, we determined using the TaqMan assay whether viral RNA was present in blood of rabies virus-injected mice. Viral RNA was detected in the blood of $30 / 32(94 \%)$ healthy mice in the early intervals (from $1 \mathrm{~h}$ to 2 days) after injection of virus (Table 3). Greater levels of viral RNA were present on the first day (threshold cycles of $<35$ ), as

Table 2

Detection of rabies viral RNA and infectious rabies virus in the identical tissue preparation: a quantification comparison ${ }^{\mathrm{a}}$

\begin{tabular}{llll}
\hline $\begin{array}{l}\text { Concentration of virus } \\
\text { injected MICLD }\end{array}$ b $^{\mathrm{b}}$ & \multicolumn{2}{l}{ Assays } & \\
\cline { 2 - 4 } & FFU $^{\mathrm{c}}$ & IV $(+)^{\mathrm{d}}$ & TaqMan $^{\mathrm{e}}$ \\
\hline $2 \times 10^{6}$ & TMTC $^{\mathrm{f}}$ & $6 / 6$ & + \\
$2 \times 10^{5}$ & TMTC $^{4}$ & $6 / 6$ & + \\
$2 \times 10^{4}$ & TMTC & $6 / 6$ & + \\
$2 \times 10^{3}$ & TMTC & $6 / 6$ & + \\
$2 \times 10^{2}$ & 159 & $6 / 6$ & + \\
$2 \times 10^{1}$ & 11 & $6 / 6$ & + \\
$2 \times 10^{0}$ & 0 & $2 / 6$ & + \\
$2 \times 10^{-1}$ & 0 & $0 / 6$ & - \\
\hline
\end{tabular}

a Ten-fold dilutions of a $10 \%$ brain suspension from paralyzed rabies virusinfected mice were prepared. Six mice were injected IC $(0.03 \mathrm{ml})$ with each dilution. MNB cell monolayers were incubated $24 \mathrm{~h}$ with $0.2 \mathrm{ml}$ of each dilution and fluorescent focus-forming units were determined. Cellular RNA from the identical dilutions was isolated and $0.03 \mathrm{ml}$ (equivalent to the volume injected IC) was evaluated for rabies viral RNA by TaqMan PCR.

b Mouse $\mathrm{ICLD}_{50} / 0.03 \mathrm{ml}$.

c Fluorescent focus units $/ 0.2 \mathrm{ml}$.

d Infectious virus detected (dead/total number of mice injected).

e TaqMan assay: $(+)<40$ threshold cycles; $(-)>40$ threshold cycles.

f Too many to count. 
Table 3

TaqMan PCR detection of rabies viral RNA in blood of mice injected IM with rabies virus ${ }^{\mathrm{a}}$

\begin{tabular}{llll}
\hline $\begin{array}{l}\text { Time after injection } \\
\text { of virus }\end{array}$ & Rabies-affected ${ }^{\mathrm{b}}$ & TaqMan & +/Total tested ${ }^{\mathrm{c}}(\%)$ \\
\hline $1 \mathrm{~h}$ & No & $6 / 7$ & \\
$3 \mathrm{~h}$ & No & $4 / 5$ & \\
$6 \mathrm{~h}$ & No & $4 / 4$ & \\
$12 \mathrm{~h}$ & No & $4 / 4$ & $30 / 32(94)$ \\
$16 \mathrm{~h}$ & No & $4 / 4$ & \\
1 days & No & $4 / 4$ & \\
2 days & No & $4 / 4$ & \\
3 days & No & $0 / 10$ & \\
5 days & No & $0 / 10$ & $0 / 37(0)$ \\
8 days & No & $0 / 10$ & \\
$15-30$ days & No & $0 / 7$ & \\
11 days & Yes & $1 / 2$ & \\
13 days & Yes & $8 / 9$ & $21 / 25(84)$ \\
14 days & Yes & $9 / 10$ & \\
16 days & Yes & $3 / 4$ & \\
& &
\end{tabular}

${ }^{a}$ Mice were injected with rabies virus in the right tibialis muscle $(0.075 \mathrm{ml}$, $10^{2}$ mouse IMLD $\left.{ }_{50}\right)$. At pre-determined intervals after virus injection, clinically healthy mice were exsanguinated directly from the heart with needle and syringe or by severing the right axillary artery. Clinically ill mice were similarly treated being exsanguinated at 2-4 days after onset of paralysis. Prior to clotting, $50 \mu 1$ of blood was removed from each sample and the sera tested for neutralizing antibody. All remaining blood including the clot was analyzed for rabies viral RNA.

b Clinically ill mice.

c Number of mice positive for rabies viral RNA/total number of mice tested (<40 threshold cycles).

compared to the second day (threshold cycles of $>35$ ). Thereafter, 3-30 days after injection of virus, viral RNA was not detected in the blood of 37 mice that remained clinically normal. In contrast, viral RNA was detected in the blood of 21/25 (84\%) mice that had developed clinical signs of rabies 11-16 days after injection of virus and were exsanguinated 2-4 days after the onset of paralysis (Table 3). Neutralizing antibody was detected in the serum of 11/21 (52\%) clinically ill mice whose blood also was positive for viral RNA.

\section{Discussion}

We have shown that the TaqMan PCR assay was highly effective in detecting rabies viral RNA in blood of mice injected i.m. with rabies virus. Viral RNA was detected at two different intervals. The first occurred $1 \mathrm{~h}$ to 2 days after injection of virus. Thereafter, RNA was not detected in blood of mice that remained free of clinical disease. It is possible that RNA present in the blood at the early intervals was due to the volume of fluid $(0.075 \mathrm{ml})$ that was injected into the muscle. The injection caused injury to blood vessels with subsequent leakage of virus into the circulation (Baer et al., 1965). Thus, the early presence of viral RNA appeared to be an artifact resulting from physical trauma and was not associated with the natural course of a murine rabies virus infection. In contrast and more importantly, the second interval in which viral RNA was detected in the blood appeared to be associated with the pathogenesis of murine rabies virus infections. In this case, viral RNA was detected in $21 / 25$ (84\%) mice that had developed clinical signs of rabies and were exsanguinated $2-4$ days after onset of paralysis. To address the possibility that a virus-infected severed nerve(s) might have "contaminated" blood collected from the severed brachial arteries, blood was also taken directly from the heart. Using either method of exsanguination, the blood of $>80 \%$ of the clinically ill mice was positive for viral RNA. The RNA present in the blood of the clinically ill mice might have been a terminal manifestation of cell destruction in the CNS and other tissues associated with viral replication that resulted in escape of degraded viral particles or possibly virus, into the bloodstream. Detectable levels of neutralizing antibody were also present in the sera of $11 / 21$ (52\%) clinically ill mice whose blood was positive for viral RNA. The presence of neutralizing antibody suggests an explanation for the negative results of previous viremia studies in which in vitro and in vivo assays were used to detect infectious virus. Other anti-viral factors (Burrer et al., 2001) might also have masked the "scoring" for infectious virus.

It is generally accepted that a viremia does not occur during rabies virus infections. This belief persists and is re-inforced by frequent references to previous imperfect studies, which show that a viremia does not occur during rabies virus infections. For example, in a review article, several papers are cited in which it is stated that a viremia does not occur during rabies virus infections (Helmick et al., 1987). Careful examination of the cited references reveals that conclusions were drawn from experiments in which infectious virus, if present, most likely would not have been detected. For instance, whole blood (apparently mixed with a non-clotting factor) was obtained from rabies-infected individuals either $8 \mathrm{~h}$ before death or at autopsy $24 \mathrm{~h}$ after death and then inoculated IC into mice (Leach and Johnson, 1940). If virus had been present in the blood, it might have been neutralized by antibody, inactivated by the time of the autopsy or inactivated by the anti-coagulant. In two additional studies, blood was allowed to clot and only the serum was inoculated IC into mice. Neither whole blood nor blood clots were tested for infectious virus and the sera were not tested for neutralizing antibody (Duffy et al., 1947; Duenas et al., 1973). An additional study reporting an absence of a viremia in rabies virus-infected animals was done in rats (Baer et al., 1965); $4 \mathrm{ml}$ of blood was drawn by cardiac puncture $3-120 \mathrm{~h}$ ( 5 days) after virus challenge, mixed with $8 \mathrm{mg}$ of heparin and allowed to stand at $4{ }^{\circ} \mathrm{C}$ for $2 \mathrm{~h}$ before the buffy coat was inoculated IC into mice. It is not mentioned whether control tests were done to determine the affect of heparin on rabies virus infectivity or whether the buffy coat from clinically ill animals was tested. And, incredulously, assays to detect a viremia were not done in two studies supporting the tenet that a viremia does not occur during rabies virus infections (Gomez et al., 1965; Warrell et al., 1976).

A more recent study testing for rabies virus RNA in blood determined that viremia does not occur in rabies-infected dogs (Sitprija et al., 2003). Blood from four naturally infected dogs was harvested at the time of death. One-tenth milliliter of blood from each dog was examined for rabies viral RNA using the RTPCR assay and a sample of blood was assayed for infectious virus in cell culture. Infectious virus was not isolated, but sera were not 
tested for neutralizing antibody. In addition, rabies viral RNA was not detected. Considering that the blood volume of a dog is $6 \%$ of the total weight of a dog and assuming the dogs weighed $15 \mathrm{~kg}$, the $0.1 \mathrm{ml}$ of blood assayed was equivalent to $0.1 \%$ of the total blood volume of a dog. We are uncertain whether the RT-PCR assay using $0.1 \%$ of the total blood volume of a dog is a fair test to detect a viremia. However, we do know that the TaqMan assay used in this study was highly sensitive detecting rabies viral RNA in $10^{-4} \mathrm{ng}$ of total cellular RNA.

In conclusion, we have determined that rabies viral RNA was present in the blood of $>80 \%$ of clinically ill rabies-infected mice. We do not know, however, whether a different rabies virus in a different model would have resulted in similar results. We also do not know whether the viral RNA was isolated from infectious virus. The state of the RNA not withstanding, the presence of rabies viral RNA in the blood suggested that there might be a risk of virus transmission after exposure to the blood of animals presenting with clinical rabies. In contrast, the risk of transmission would appear to be minimal if animals were not clinically ill. Lastly, the current opinion that a viremia does not occur during experimental or natural rabies virus infections of other species might need to be re-evaluated.

\section{Acknowledgements}

We thank K. Hasenkrug, J. Portis and R. Race for critical review of the manuscript; G Hettrick and A. Mora for graphic arts assistance; the staff of the Rocky Mountain Laboratories Veterinary Branch for care of the mice.

\section{References}

Atanasiu, P., Guillon, J.C., Vallee, A., 1970. Contribution a l'etude de la rage experimentale du renard. Ann. Inst. Pasteur. 119, 260-269.

Baer, G.M., Shanthaveerappa, T.R., Bourne, G.H., 1965. Studies on the pathogenesis of fixed rabies virus in rats. Bull. WHO 33, 783-794.

Baratawidjaja, R.K., Morrissey, L.P., Labzoffsky, N.A., 1965. Demonstration of vaccinia, lymphocytic choriomeningitis, and rabies viruses in the leucocytes of experimentally infected animals. Virusfarsch XVII, 273-279.

Becker, P., Zunker, M., 1980. Different behaviour of street rabies and virus fixe strains in parabiotic rats (author's translation) [Uber das unterschiedliche verhalten von strassenwut-und virus fixe-stammen bei parabioseversuchen mit ratten]. Zentralbl. Bakteriol. A 247, 290-295.

Borodina, T.A., 1958. A study of viraemia in experimental rabies. Probl. Virol. 4, 96-100.

Burne, J.C., 1970. Viremia in rabies. Lancet 1, 195-196.

Burns, K.F., Shelton, D.F., Lukeman, J.M., Grogan, E.W., 1960. Cortisone and ACTH impairment of response to rabies vaccine. Public Health Rep. $75,441-445$.

Burrer, R., Salmon-Ceron, D., Richert, S., Pancino, G., Spiridon, G., Haessig, S., Roques, V., Barre-Sinoussi, F., Aubertin, A.M., Moog, C., 2001.
Immunoglobulin $\mathrm{G}$ (IgG) and IgA, but also nonantibody factors, account for in vitro neutralization of human immunodeficiency virus (HIV) type 1 primary isolates by serum and plasma of HIV-infected patients. J. Virol. 75, 5421-5424.

Dean, D.J., Evans, W.M., McClure, R.C., 1963. Pathogenesis of rabies. Bull. WHO 29, 803-811.

Duenas, A., Belsey, M.A., Escobar, J., Medina, P., Sanmartin, D., 1973. Isolation of rabies virus outside the human central nervous system. J. Infect. Dis. 127, 702-704.

Duffy, C.E., Woolley Jr., P.V., Nolting, W.S., 1947. Rabies: a case report with notes on the isolation of the virus from saliva. J. Pediatr. 31, 440447.

Gomez, M.R., Siekert, R.G., Herrmann, E.C., 1965. A human case of skunk rabies: a case report with comment on virological studies and the prophylactic treatment. JAMA 194, 333-335.

Gribencha, S.V., Barinsky, I.F., 1982. Viraemia in rabies. Acta Virol. 26, 301.

Helmick, C.G., Tauxe, R.V., Vernon, A.A., 1987. Is there a risk to contacts of patients with rabies? Rev. Infect. Dis. 9, 511-518.

Hughes, G.J., Smith, J.S., Hanlon, C.A., Rupprecht, C.E., 2004. Evaluation of a TaqMan PCR assay to detect rabies virus RNA: influence of sequence variation and application to quantification of viral loads. J. Clin. Microbiol. 42, 299-306.

Kitselman, C.H., et al., 1967. Pathogenesis of rabies in the rat. Can. J. Comp. Med. 31, 122-124.

Leach, C.N., Johnson, H.N., 1940. Human rabies, with special reference to virus distribution and titer. Am. J. Trop. Med. 20, 335-340.

Lodmell, D.L., 1983. Genetic control of resistance to street rabies virus in mice. J. Exp. Med. 157, 451-460.

Lodmell, D.L., Ray, N.B., Parnell, M.J., Ewalt, L.C., Hanlon, C.A., Shaddock, J.H., Sanderlin, D.S., Rupprecht, C.E., 1998. DNA immunization protects nonhuman primates against rabies virus. Nat. Med. 4, 949-952.

Murphy, F.A., 1977. Rabies pathogenesis: brief review. Arch. Virol. 54, 279-297.

Murphy, F.A., Bauer, S.P., 1974. Early street rabies virus infection in striated muscle and later progression to the central nervous system. Intervirology 3, 256-268.

Schindler, R., 1961. Studies on the pathogenesis of rabies. Bull. WHO 25, $119-126$.

Schindler, R., 1965. Pathogenesis of rabies infection. In: International Symposium on Rabies, Talloires. Karger, Basel/New York, pp. 147-152.

Schweinburg, F., 1930. Ueber den Ausbreitungsweg des Wuterregers von der Eintrittspforte aus. Virchows. Arch. Pathol. Anat. 178, 23-34.

Shukeir, A.A., Nosik, N.N., 1965. The effect of cortisone on immune reactions in rabies. Acta Virol. 9, 472-477.

Sims, R.A., Allen, R., Sulkin, S.E., 1963. Studies on the pathogenesis of rabies in insectivorous bats. Part III: influence of the gravid state. J. Infect. Dis. 112, 17-27.

Sitprija, V., Sriaroon, C., Lumlertdaecha, B., Wacharapluesadee, S., Phumesin, P., Khawplod, P., Wilde, H., Hemachudha, T., 2003. Does contact with urine and blood from a rabid dog represent a rabies risk? Clin. Infect. Dis. 37, 1399-1400.

Smith, J.S., Yager, P.A., Baer, G.M., 1973. A rapid reproducible test for determining rabies neutralizing antibody. Bull. World Health Org. 48, 535-541.

Warrell, D.A., Davidson, N.M., Pope, H.M., Bailie, W.E., Lawrie, J.H., Ormerod, L.D., Kertesz, A., Lewis, P., 1976. Pathophysiologic studies in human rabies. Am. J. Med. 60, 180-190. 